\title{
Gastro Diplomacy and French Cuisine: Towards Divining a Gastro-Cultural Heritage between Paris and Puducherry
}

\author{
E. Devabalane ${ }^{1^{*}}$ and Marie Josephine Aruna ${ }^{2}$ \\ 1Assistant Professor of Tourism, Tagore Arts College, Puducherry, India; devabalane@gmail.com \\ ${ }^{2}$ Assistant Professor of English, Bharathidasan Government College for Women (Autonomous) Puducherry, India
}

\begin{abstract}
Puducherry has a unique ambience of colonial culture and ethnicity because of its connections with France for more than 138 years, creating a niche for heritage and gastronomical practices till today that stands as a living monument of French culture. France's greatest treasure is its rich cuisine. The French have an ongoing love affair with food and beverages and their reverence in eating is evident throughout the world especially in Puducherry. French cuisine is one of the most popular types of food for its quality attracts several visitors to eat and talk a lot of all ages because of a homely social life in restaurants. There are two traditions running through French cooking, la hautecuisine as practised by the great chefs and restaurants and la cuisineregionale which consists of the natural specialities utilising the best local and seasonal ingredients. The notable aspect in the faculty of history is the study of heritage where food takes centre stage in revealing the nuances of culture and where Paris is the gastronomical capital of the world. French food is unique, a cultural experience that moulds flavourful, nutritious food with beauty, leisure, and therapeutic preparations. The symbolism inherent in any shared meal has the ability not only to create relationships between the countries and difficult to define them as well. As ubiquitous tools in the art of statecraft, diplomatic meals give participants and planners the opportunity to predict, identify, and fully understand the subtle messages such occasions create. A solid understanding of the semiotics of diplomatic gastronomy will allow researchers to decode and analyze state dinners and other diplomatically significant meals. The present study emphasises on French food as a heritage product and how stereotypical French dishes are still prevalent among the peoples of Puducherry inculcating a sense of pride. How French food becomes Unique Selling Preposition (USP) as well as the identity of the destination for the rich experiences creating added value for the cultural promotion is analysed. The paper deals with primary and secondary sources of information and the findings of the study will showcase the rich French legacy and lifestyle of the peoples of Puducherry.
\end{abstract}

Keywords: French Legacy, Gastronomical, La Cuisineregionale, La Hautecuisine, USP

\section{Introduction}

French food is the most popular types of cuisine around these days and is known worldwide for its quality. French cuisine is a unique, cultural experience that melds flavourful, nutritious foods with beauty, leisure and therapeutic preparation. French cuisine has its own history and heritage like many other regional native cuisines and is still continuing to push the boundaries of the gastronomic world. In fact there is no doubt that, one of the modern France's greatest treasures of all times is its rich cuisine. The French have an ongoing love affair with food and wine, and their reverence for time spent in eating is evident in any culinary establishment in all parts of France. The Cuisine is not food, it is food transcended, and transformed into a sociallyaccepted product, like an aesthetic artefact, a linguistic creation, and a cultural tradition. The importance of cuisine in France, its prestige at home and abroad are

${ }^{*}$ Author for correspondence 
a consequence of the role played by the culinary system of the institutions which diffuse the discoursalimentaires. It was diffusion that changed la grande cuisine into la cuisine francaise [4]. French cooking is considered as an art form, has its roots in the past, but remains in a constant state of evolution. Pondicherry is the French interpretation of the original name Puducherry meaning "new settlement". The legend says that the sage Agastya established his Ashram here and the place was known as Agastiswaram and the excavations at Arikamedu, about $7 \mathrm{kms}$ to the south of Puducherry, shows that Romans came here in the 1st Century AD for establishing Mari-time trade. In 1674, Francois Martin, the first French Governor, transformed Pondicherry from a small fishing village into a flourishing port-town. From the 18th century, the town was laid out on a grid pattern with effective planning in art and architecture and grew considerably as what we witness in France. The battle between the English and French changed the fortunes of Puducherry has a remarkable destination. In 1761, Puducherry was razed to the ground in revenge and lay in ruins for four years and only after 1816 the French regained its permanent control of Puducherry ruling for 159 years continuously. In 1954, the French handed Puducherry over to independent India [2].

\section{History of French Cuisine}

France got most of its notoriety because of the fact that they were ruled by so many different people. The country had established itsculinary art in the mid of $15^{\text {th }}$ century by the wife of Henry II, Catherine de Medici of Italy. She brought Florentine educated cooks with her and wherever they went there was a sense of creative drama and manners. The period between the $16^{\text {th }}$ and $17^{\text {th }}$ century was also known as Ancient Regime, where Paris was referred to as the central hub of culture and economic activity and the most highly skilled culinary craftsmen were available. During that period, food distribution was regulated by the city government in the form of guilds, and these guilds put in place lot of restrictions to operate in the prime areas of France. Between the $17^{\text {th }}$ and $18^{\text {th }}$ century, leads for further development like Haute cuisine or High Cuisine and its origin can be found in the recipes named after chef La Varenne. His cook books focussed new recipes which highlights on more modest and less extravagant French meals. Meanwhile the French revolution also brought a turning point in the French food industry, which led to the failure of guilds and allows more chefs to establish and experiment with different types of ingredients and dishes. During that period, the most prominent chefs emerged was Marie-Antoine Careme. Antoine based his cooking around the development of what we called as his Mother sauces. Many of his sauces are still being used even today in French cuisine. During the late $19^{\text {th }}$ and $20^{\text {th }}$ century began the modernization of haute cuisine developed by George Auguste Escoffier. Most of his method was derived from the recipes of Caremeand developed a new modern French cuisine and become more professional. He established a Brigade system which divides French kitchen into five sections. The sections includes "grand manger" that prepared cold dishes, the "entremettier" prepared starches and vegetables, the "rotisseur" prepared roasts, grilled and fried dishes, the "saucer" prepared sauces and soups, and the "patissier" prepared all pastry and dessert items. After Escoffier, many changes have been placed in the anatomy of French cuisine, new techniques have emerged and chefs have become more creative. Today the French meal structure is divided into Le petit dejeuner, Le dejeuner, Le diner (Breakfast, lunch, dinner).Wine plays a vital role in French meals and varieties of wine like red, white, and rose is paired with each course in a meal, accordingly wine is selected and served for each course [1].

\section{Paris to Puducherry - A Report}

According to the historians the largest French colony in India was Pondicherry which has a long classical history of trade and war in modern times. Even now one can visualise the strong French influence in the city, while visiting the old quarters, with streets (Rues) and Boulevards lined with Mediterranean styled built houses. In Puducherry, French culture is still understood, in every walks of life and the whole city makes a pleasant mélangeof the East and West and marks the space as The French Riviera of the East ( $\mathrm{La}$ Côte d'Azur de l'Est). With Francois Martin, the French began to take root in Puducherry. He was replaced by Dumas and saved Puducherry from the Marathas stating that as long as one French man remained alive, Puducherry could not be evacuated. Dumas gave him thirty bottles of Nantes Cordials. Long live liquor! It saved Puducherry from the threat of the unruly Marathas [5]. From this historical event one can understand how liquors from France come to Puducherry. The next Governor was Monsieur Joseph Francois Dupleix, had one aim, one business and one desire, and that was to establish a French colonial empire in India influencing the French culture in all walks of life during his regime, and Madame Dupleix, was very particular in introducing French foods among the Puducherrians, is noteworthy evidence how culture and cuisine travelled all along from Paris to Puducherry. 
If anyone reaches Pondicherry by land, one will be culturally astonished to see Paris style of architecture and restaurants serving steak and wine. It is not just French cuisine that blends with a Tamilian style of cooking and there are also influences of the Portuguese, Malaysian and Mughals, among others. The Pondicherry Kitchen book written by Lourdes Tirouvanziam-Louis, says that Indian cuisine, as a whole, finds its basic unity in the use of spices and seasonings based on a variety of flavours. The French food has been adapted and the basic ingredients have been retained and practiced still in most of the houses and some of the French dishes had been modified with Indian spices to suit the local milieu. Some of the rich ingredients were introduced in the French dishes, like ghee, coconut milk, almond milk, poppy-seed paste and cashew-nut paste just to tone down the spices of the south without the losing the aesthetic sense of the Paris in the land of Puducherry. .

\section{Objectives of the Study}

The present paper tries to attempt and to explore the fascinating development of the French cuisine with the following objectives:

- To know the historical back ground of French cuisine

- To explore the gastro- cultural heritage in Puducherry

- To identify the preference of French cuisine in Puducherry by tourists

- To identify the preference of drinking venue among tourists to Puducherry

- To show case the predominant French dishes in Puducherry

\section{Methodology}

In this study, the history of French cuisine is analyzed through secondary sources, and also the gastro- cultural heritage in Puducherry is vividly explained. The study deals with primary data by 200 samples with self - administered questionnaire from both domestic and international tourists during the month of December 2013 and January 2014, by convenience sampling technique. In this empirical study the following statistical tools had been used to analyze the data which includes percentage, mean, standard deviation, $t$-test and $f$-test.

\section{Gastro-Cultural Heritage}

One of the most urgent and basic needs of humanity is food. It would also be apt to say that food is life because it is our very sustenance. Food sustains a human being's very existence. However, anthropologists like Claude Levi Strauss and Roland Barthes argue that food has greatly influenced the very culture of societies and it has gone beyond serving its nutritional and physiological purposes, in that food has become a system of communication, almost like language with rules not unlike grammar [3]. Food as a structure therefore imposes order on our everyday life, shaping human experiences, thereby reflecting not only knowledge about food but at the same time is inseparable from people's social, political, historical, economic and cultural contexts. The UNESCO in November 2010 declared the French multi-course gastronomical practices as added to the lists of the world's Intangible Cultural Heritage. UNESCO describes the reason for having nominated the French cuisine as an intangible cultural heritage for the following reasons:

1. French food as a social practice for celebrating all social, cultural and personal moments.

2. French food brings the people together for the social harmony and cohesion.

3. French food always goes with wine along with beautiful ambience.

4. Varieties of dishes with sauces and beverages before the meal and other courses with anapéritif (drinks before the meal) and ending with liqueurs

According to the statement released by the UNESCO, the speciality of the French meal, draws circles of family and friends closer together and, more generally, strengthens social ties" (UNESCO Culture Sector- Intangible Heritage -2003 Convention).

The term "Gastronomy" (the science of the study of food) was derived from the Greek word Gaster meaning 'stomach' and nomos meaning the art or laws that governs and regulates the stomach.Gastronomy involves discovering, tasting, experiencing, researching, understanding and writing about food preparation and the sensory qualities of humannutrition as a whole. It also studies how nutrition interfaces with the broader culture (Gastronomy -Wikipedia). The gastro diplomacy is the easiest way to win hearts and minds through the stomach. "It is used to define everything from fine-dining experiences to specific studies of the chemical manipulation of food. The French cuisine with its rites and its presentation exhibits the French love for getting together to eat and drink well and enjoy good times in such a manner which is part of their tradition, a quite active tradition. Even in matters of how wines, a significant cultural tradition of the French dining habits which is a result of their regional produce, are paired with 
dishes, of how the table is dressed, the precise placing of glasses, for water, red and white wine, knife blade pointing in and fork tines down, are all seen as part of the rite. French lunch is even considered to be one of the most treasured cultures. The French people feel that for centuries, they have been convinced that nothing is so fine, so culturally satisfying, so spiritually uplifting as sitting down for a good French meal with friends and family. Since the UN has for the first time honoured a gastronomical practice as an intangible cultural heritage, is the French cuisine and the people take great pride in their highly structured and religiously followed dining ritual that commences from aperitif to appetizer, with the ambience of love, laughter, and life. Its process of cooking as well as eating is a lived experience that gives gratification to all. To such a customary gastronomical practice, the French are the first to claim their own, compared to the rest of the world. France's gastronomical meal ritual is as important as the food itself. Hence the art of selecting, preparing, serving, and enjoying fine food is a passion with the French, an adventure, and has a story to tell. Coming to its influence over foreign cultures, other than the Western, France being the second imperial powers of the world in the history of colonization, next only to England, has naturally contributed to the dissemination of its culture to those regions of the world that came under its occupation. Whereas the British imperialism in India was one of the ruler and ruled relationships, the French connection with the country in particular its relation to Puducherry was not one of a strictly master slave theory. Therefore the integration of the French culture especially including its language, food, and architecture into the colony became simple and easy. When the natives started cooking for the French people, they had to work in conjunction with their counterparts -the French chefs who taught them the art of French gastronomic rituals and practices. For instance, the second author's association with one monsieur Nolan a police constable, in her youthful days recalls how he used to narrate his experiences of having worked as an orderly for the white bosses, wherein he was inculcated with the cooking methodology of French dishes. He thereby imbibed the knowledge of French culinary practices which in turn he adopted for his Indian bosses once the French lords left the town. The knowledge that he had obtained directly from the French were in turn transferred to the new/Puducherrian household that he was working for. And another important factor was that not just the actual making of the food but the spreading of it, setting the table, arrangement of the plates and glasses, fork and spoon etc. all these were perfectly followed according to the French style. Even the dishes used for serving and eating were crockery made of porcelain, and the right kind of dish was used for different segments followed during the course of a meal, meant for the soup, salad, main course or the dessert or even for the wine or water. What he had seen, observed, learnt, and practiced was later on passed on to others who our mothers, who too had seen, observed, learnt and practiced in their homes. Likewise many other families too would have such French connections whereby they have been cooking French food for generations as a result of direct contacts with the French chefs. Hence the French cuisine as a culinary art form and its nuances were passed on from one generation to another orally and continue to be in practice.

There is yet another means, through which the gastronomical practices of the French were adopted, practiced and continues to be prevalent in the Puducherry families. This can be traced to the fact that once the French had left India, the Puducherrians were given the option of remaining as French nationals though they continued to live in India- and Puducherry itself opting to be part of the Indian Union. Moreover the French Consulate was established in Puducherry to serve the French Indians in Puducherry. The second author's grandfather whose parents had worked for the French in Saigon in Vietnam, which was also a French colony, paved way for their son to take up employment with the French once the Consulate had been established both prior to and after the French occupation. The author's grandfather had thus a close association with the French as officer of the court (greffier) under French rule and in the independent Puducherry as chef de bureau militaires on the staff of the Consulate. He had also served the French government in its African colony of Yaoundé, the French capital of Cameroon. He had but to imbibe the French culture-its language, customs and food habits. He had to host a number of parties where it was the French way of dining, starting with an aperitif or appetizer session, followed by the hors doeuvres, or entrees, then the plat principal (main course), and a cheese course or dessert, sometimes with a salad offered before the cheese or dessert. The meal is often accompanied by bread and wine. Right from the preparation to the setting of the table, to the serving and eating, every aspect of the dinner is followed meticulously according to the French manner.Another significant factor that contributes to the French gastro-cultural heritage is its emphasis on the Sunday lunch with the whole family gathered together at the grandparents' which UNESCO too has recorded as the means of passing on the culture from generation to generation. A Sunday lunch in most of the families in puducherry is a coming together of its members who partake of the French style cuisine. For no reason 
the Sunday lunch is missed by the members of the family. An elaborate lunch at home with several courses of meal in the company of relatives and friends is preferred to eating out at restaurants. During the course of the meal a lot of socializing and communion among the family members is the highlight with discussions ranging from politics to personal that makes every member from the old to young to look forward to Sundays. There is lot of sharing, happiness and fun across the table. Thanks to the second author's grandfather who inculcated this happy French eating custom in the family that is practiced even today. The dishes retain not only their original flavor but also the name that is also pronounced in its original French form. With the annual visit of others members of the families who have chosen to live in France, the traditions and customs of the French cooking style and gastronomical practices are retained to a larger extent.

Puducherry also being the window to French culture attracts a lot of tourist inflow throughout the year both from France, elsewhere of the world as well as from India. Therefore as a tourist destination we need to look into the fact of how French gastro-cultural practices allure the outsiders to this little coastal town, a yester year colony of France to taste the predominantly French food offered by its restaurants to the French as well as non-French tourists as per their preferences.

\section{Preference of French Cuisine by Tourist}

Food is the major tourism product, which could influence the retention of tourists at a destination. As the considerable number of tourists are food conscious and take only specific items, availability of proper kind of food would increase the tourists' inflow. On the other hand, few tourists may also be willing to taste the different varieties of cuisine available locally. The above scenario gives impli- cations to tourism marketers to fulfil the interests of the tourists with regard to food, cuisine, etc.

It is seen from Table 1, 38.5\% of domestic and 39.5\% of international tourists (39\% of total sample) preferred cuisine available locally in Pondicherry. This is followed by French cuisine with $32 \%$ of domestic and $25.5 \%$ of International visitors. It can also be seen from the table that there was a considerable number of domestic (24\%) and foreign (22\%) tourists who preferred continental food available in Pondicherry. While $13 \%$ of the foreign tourists showed their interest in self-cooked foods, only 5.5 of domestics were interested in it. From the above results, it is seen that only in respect of local cuisine both domestic and international tourists were in accordance with each other. But, in respect of other food varieties, the scenario is different. That is, preference to French, Continental and self-cooked food varieties do vary between domestic and international tourists. Further, value of contingency coefficient is also significant at 5\% level. This in turn indicates that kind of food preferred between domestic and international tourists differ significantly.

\section{Tourists and their Preferred Venue for Eating and Drinking}

It is known that French food is heavy in saturated fats, creams, sauces and butter in many dishes, moreover they prefer to eat accompanied with wine and other beverages and also the venue and ambience matters a lot. The French restaurants in Puducherry are a combination of promiscuity and privacy, effectively isolating the individual or small group. Many people are restrictive to consuming alcohol and very conscious about the place of eating and drinking. For tourists who like to have drinking, the environment is the most important. Some people would like to have it in a bar and some other in the cabin of a bar while some people may prefer to have it in a room environment because of

Table 1. Distribution of tourists on the basis of food preferred (In Percentage)

\begin{tabular}{lccc}
\hline Food Preference & Domestic Tourists & International Tourists & Total \\
\hline Local Cuisine & 38.5 & 39.5 & 39.0 \\
French cuisine & 32.0 & 25.5 & 28.8 \\
Continental & 24.0 & 22.0 & 23.0 \\
Self-Cooked & 5.5 & 13.0 & 9.3 \\
Total & 100.0 & 100.0 & 100.0 \\
Coefficient of Contingency & 0.1379 & Significant @ 5\% level. \\
\hline Source: Primary Data & & &
\end{tabular}


Table 2. Distribution of tourists on the basis of ambience preferred by them to drink and eat (In Percentage)

\begin{tabular}{lccc}
\hline $\begin{array}{l}\text { Ambiance for Eating and } \\
\text { Drinking }\end{array}$ & Domestic Tourists & International Tourists & Total \\
\hline No such habit & 29.0 & 6.0 & 17.5 \\
In the open air restaurant & 24.5 & 29.5 & 27.0 \\
Cabin of a bar & 14.0 & 11.5 & 12.8 \\
In your own room only & 12.5 & 3.0 & 7.8 \\
In open air bar & 17.0 & 40.5 & 28.8 \\
Anywhere & 3.0 & 9.5 & 6.3 \\
Total & 100.0 & 100.0 & 100.0 \\
Coefficient of Contingency & 0.3842 & Significant @ 1\% level. \\
\hline Source: Primary Data & & &
\end{tabular}

privacy and some may want drinks to be served in the open air.

Observation of Table 2 indicates that $29 \%$ of the domestic and $6 \%$ of the international tourists $(17.5 \%$ of total same) never took to drinking. Among the tourists with drinking habits, $27 \%$ of the total sample tourists wanted drinks to be served in the open air $(24.5 \%$ of domestic and $29.5 \%$ of internationals). The table further shows that $40.5 \%$ of foreigners were interested to drink in the open-air bar, whereas it was $17 \%$ in the case of domestic tourists.

It is also seen that substantial number of domestic tourists (12.5\%) preferred drinks and food in their rooms and very few of the international tourists $(3.0 \%)$ preferred to have privacy during drinking. It is also clear that the number of cases of 'anywhere to drink' is 3\% for domestic and $9.5 \%$ for international front. The table further depicts that the coefficient of contingency is significant at $1 \%$ level (0.3842, $\mathrm{p}<0.01)$, which in turn exposes that place of preference for taking alcohol differ remarkably between domestic and international tourists (Table 2).

\section{Most Common French Dish of Puducherry}

The French love to eat and everywhere you go in France you will find exquisite food, prepared and cooked with infinite carefrom the finest and freshest ingredients, the same culinary culture is also seen in Puducherry is the proof of the French food as a diplomatic product. Some of the common dishes prepared by Franco-Puducherrians and the ingredients that are useful for preparing, are Cheeses, garlic, onion, olives, olive oil, herbs, mushrooms, mustard, snails, wine foiegras, bouquet garni, confitd"oie, chives, thyme.
Some of the French dishes are Soupe A L'Oingnon( French onion soup), Souffle Au forage ( cheese soufflé), Piperade (hot pepper omelette), Crepes De Fruits De Mer ( seafood pancakes), Tournedos En Croute (Fillet steak in pastry), Gigot Au Pistou (leg of lamb with garlic stuffing), Coq Au Vin (Chicken in red wine), Poulet Basqaise( Basque-style chicken), Salade De LentillesTiede( Warm lentil salad), Galettes De Pommes De Terre (Pototo cakes). Crepes Suzette (Sweet orange pancakes), Crème Caramel (caramel custard). Mayonnaise (Salad dressing), Vinaigrette ( French oil and vinegar dressing). Out of which the most preferred dish is Boeuf a la Bourguignonne and Coq au Vin is a must -taste classic recipes of the French cuisine.

\section{Conclusion}

The French cuisine has a rich history like many other native cuisines of the world. It is known from the study, how the French food continues to evolve and change in other boundaries of the culinary continent. Paris has been revered as one of the world's most refined culinary locations with more than 9000 restaurants and the movement also began in Puducherry with long held traditions and gastro-cultural heritage. French food is best accompanied by wine creating "the French paradox." The French cuisine is highly sophisticated, varied, well balanced on local ingredients and high quality products with the combination of traditional and nouvelle, to be a great delight of everyone around the world is not an exaggeration but a fact according to UNESCO who has awarded the French cuisine as a intangible cultural heritage. Throughout the history food has offered people the opportunity for communication and exchange. Country's food and eating habits can be consid- 
ered as intrinsic to national identity, touching all parts of history, economy, culture and society creating strong gastro diplomacy among nations by winning the hearts and mind of the people and tourists through the stomach.

\section{References}

1. Colin, Y. "History of French Cuisine". Available: http:/www. personal.psu.edu/srh/122/French.htm, accessed on 12-122013

2. Devabalane, E. Tourism Industry - An introspective vision, Komugipathipagam, 2010. Pp. 56-65.
3. Dusselier, J. "Understanding of Food as Culture", Environmental History, vol. 14(2), pp. 331-338, 2009. Available: http//www.jstor.org./stable/40608476.

4. Priscilla, P.C. “Thoughts for Food, I: French Cuisine and French Culture", The French review, vol. 49, pp. 32-36, 1975.

5. Raja, P.A. Concise History of Pondicherry, Busy Bee Books; 2003. pp. 30-32.

\section{Other References}

1. French Cooking Recipes. Available: www. cuisine-France. com

2. Available: French Cuisine.en.wikipedia.org./wiki/French cuisine. 